\title{
THE INTEGRATION OF ONLINE TEACHING AND LEARNING IN STEM EDUCATION AS A RESPONSE TO THE COVID-19 PANDEMIC
}

\author{
Lindelani Mnguni \\ University of the Witwatersrand, South Africa \\ Hamza Mokiwa \\ University of South Africa, South Africa
}

\section{Introduction}

Science, Technology, Engineering, and Mathematics (STEM) education curriculum and instructional design continuously undergo reforms that aim to prepare learners for the challenges of the $21^{\text {st }}$ century (Hoeg \& Bencze, 2017; Pietarinen et al., 2017). In particular, STEM education has adopted strategies that integrate modern technologies in teaching and learning to enhance knowledge construction and application among learners and societies. In some countries, STEM education reforms are fuelled by socio-economic and political imperatives that seek to promote social justice (Mnguni, 2018). More recently, the emergence of the Covid-19 pandemic has forced schools and universities to adopt online teaching methods to reduce the coronavirus's spread. Consequently, researchers are exploring strategies for the incorporation of online teaching and learning methods. The effectiveness of these strategies and their impact on the students' conceptualization of STEM knowledge, its application, and relevance are continuously being investigated.

The application and relevance of online teaching and learning in STEM education can be viewed within the context of the $4^{\text {th }}$ industrial revolution (Penprase, 2018). Research has shown that integrating digital learning technologies improves students' conceptualization of STEM knowledge (Kelley \& Knowles, 2016). There is a need to explore how these online teaching and learning methods could be used in diverse contexts, particularly in under-resourced and rural areas. In addition to digital learning technologies, the $21^{\text {st }}$ century has seen the rise in technologies such as robotics, virtual reality (VR), and artificial intelligence (Al). However, the role of these technologies in the teaching of STEM education has not been explored extensively. Furthermore, teachers and learners' teaching and learning skills to effectively use these technologies require extensive research.

\section{The Urgency for STEM Education Research during the Covid-19 Pandemic}

While instructional designers have explored various strategies for integrating online teaching and learning in STEM education, the Covid-19 pandemic has exacerbated the urgency for online teaching and learning. With this urgency has emerged that critical research questions should be addressed to ensure that the quality of teaching and learning in STEM education is not compromised. Firstly, there is a need to determine the impact of Covid-19 on teaching and learning in STEM education. This impact could relate to student development, curriculum design, pedagogy, and assessment. Secondly, strategies for integrating online teaching and learning methods in STEM education need to be explored. Related to this, there is a need to address classroom practices and infrastructure 
requirements for adopting online teaching and learning methods in the Covid-19 pandemic. Thirdly, there is a need to explore teacher preparedness to adopt online teaching methods in STEM education as a response to the Covid-19 pandemic. In particular, the issues related to attitudes, intentions, behaviours related to online teaching, and how these could be enhanced through professional development should be addressed. Finally, there is a need to investigate opportunities for 4IR technologies in STEM education to enhance online teaching and learning integration.

\section{The Current Special Issue 'Responding to Covid-19: The Integration of Online Teaching and Learning in STEM Education'}

In this context, the current special issue seeks to create a platform through which researchers and curriculum and instructional designers can share their experiences and strategies for online learning to enhance the quality of STEM education. Therefore, papers in the current special issue explore strategies for online teaching and learning methods in STEM education, and the effectiveness and impact of these strategies across the different STEM disciplines. This includes exploring the following areas:

- The role of the Covid-19 pandemic as an agent of change in teaching and learning in STEM education.

- Strategies adopted by STEM educators to transform their pedagogical practices as an integral part of the transition to online teaching and learning in response to Covid-19.

- Teacher perceptions of the effectiveness, risks and opportunities afforded by their adopted pedagogical practices on students' development.

- Challenges faced by teachers when adopting online teaching strategies as a response to the Covid-19 pandemic.

- Coping strategies adopted by STEM educators as an integral part of transforming their pedagogical practices during the Covid-19 pandemic.

- $\quad$ STEM educators' perceptions and attitudes towards virtual laboratory experiments as a teaching method during the Covid-19 pandemic

\section{Conclusion}

The research reported in the articles in the current special issue shows that teachers have adopted various online teaching strategies with the Covid-19 playing a critical role as an agent of change. However, this research also suggests that there may be numerous teaching and learning challenges that could negatively affect learner development and compromise teaching and learning in STEM education. This is mainly because some teachers were not adequately prepared to transform their pedagogical practices.

While the current special issue addresses critical questions in STEM education, they also highlight the urgent need for global dialogue on best practices to enhance online teaching and learning in STEM education. This is because the $21^{\text {st }}$-century technologies will continue to evolve as part of the $4^{\text {th }}$ industrial revolution. Therefore, while Covid-19 may have been an essential agent of change, there needs to be a dialogue about teaching and learning practices in STEM education, beyond the Covid-19 pandemic.

\section{Acknowledgement}

The Editorial Board thanks the guest editors L. Mnguni (University of the Witwatersrand) and H. Mokiwa (University of South Africa) for their efficient work in preparing this special issue of JBSE. The Editorial Board certainly wish you the best of luck in this exciting endeavor!

\section{References}

Hoeg, D. G., \& Bencze, J. L. (2017). Values underpinning STEM education in the USA: An analysis of the Next Generation Science Standards. Science Education, 101(2), 278-301. https://doi.org/10.1002/sce.21260

Mnguni, L. (2018). Citizenship education and the curriculum ideologies of Natural Sciences and Life Sciences curricula in South Africa. Curriculum Perspectives, 38(2), 97-106. https://doi.org/10.1007/s41297-018-0044-z

Pietarinen, J., Pyhältö, K., \& Soini, T. (2017). Large-scale curriculum reform in Finland-exploring the interrelation between implementation strategy, the function of the reform, and curriculum coherence. The Curriculum Journal, 28(1), 22-40. https://doi.org/10.1080/09585176.2016.1179205 
Penprase, B. E. (2018). The fourth industrial revolution and higher education. In N. W. Gleason (Ed.), Higher education in the era of the fourth industrial revolution (pp. 207-228). Palgrave MacMillan https://doi.org/10.1007/978-981-13-0194-0_9

Kelley, T. R., \& Knowles, J. G. (2016). A conceptual framework for integrated STEM education. International Journal of STEM Education, 3(1), 11. https://doi.org/10.1186/s40594-016-0046-z

\section{Lindelani Mnguni (Corresponding author \& Guest editor)}

Hamza Mokiwa

(Guest editor)
$\mathrm{PhD}$, Assistant Dean, Centre for Health Sciences Education, Faculty of Health Sciences, University of the Witwatersrand, Johannesburg, South Africa. E-mail: lindelani.mnguni@wits.ac.za ORCID: https://orcid.org/0000-0002-0361-0002

$\mathrm{PhD}$, Senior Lecturer, Department of Science \& Technology Education, University of South Africa, Preller Street, Pretoria, South Africa.

E-mail: mokiwho@unisa.ac.za

ORCID: https://orcid.org/0000-0002-1676-449X 